\title{
Accelerated Partial Breast Irradiation: Where Do We Stand?
}

Frederick M. Dirbas, MD, Stanford, California

\author{
Key Words \\ Accelerated partial breast irradiation, APBI, breast cancer, brachyther- \\ apy, IORT, 3D conformal radiotherapy, clinical trials
}

\begin{abstract}
Accelerated partial breast irradiation (APBI) is a new form of postlumpectomy radiotherapy delivered over 1 to 5 days. Early trials showed high local recurrence rates. More recent single and multiinstitutional studies, as well as a single phase III trial, have shown local control more comparable to whole breast radiotherapy. Patient selection and surgical technique are important variables preparatory to irradiation, which is delivered using 1 of 4 accelerated radiotherapy methods. Phase I/II studies have produced most of the information currently available regarding APBI. Additional phase III studies are underway to determine whether any or all of these accelerated radiotherapy approaches may safely substitute for whole breast radiotherapy in women seeking breast conservation. (JNCCN 2009;7:215-225)
\end{abstract}

Lumpectomy followed by 5 to 7 weeks of whole breast radiotherapy (WB-XRT), known as breast conservation ther$a p y$, is a standard approach to early-stage breast cancer. WB-XRT is typically delivered using 2 opposing tangent fields with a boost dose to the lumpectomy cavity. This therapy affords comparable survival to mastectomy with low rates of recurrence and acceptable cosmesis for most women. ${ }^{1,2}$

Newer strategies of breast conservation therapy involving shorter courses of WB-XRT have been developed. A randomized trial evaluating postlumpectomy

From the Stanford Cancer Center and Department of Surgery, Section of Surgical Oncology, Stanford University School of Medicine, Stanford University, Stanford, California.

Submitted November 10, 2008; accepted for publication December 18,2008

The author owns stock in Hologic, Inc. and Cianna Medical, Inc. Correspondence to: Frederick M. Dirbas, MD, Stanford University, 875 Blake Wilbur Drive, CC2235, Stanford, CA 94305.

E-mail: dirbas@stanford.edu
WB-XRT over 3 weeks showed comparable rates of local tumor control, survival, and cosmesis as the traditional 5- to 6-week course of therapy. ${ }^{3}$

Accelerated partial breast irradiation (APBI) offers even shorter treatment times while limiting the radiation field. This new approach is based on 2 observations: 1) most in-breast tumor recurrences occur in the immediate vicinity of the lumpectomy cavity, and 2) as the radiation field decreases in volume, shorter courses of radiation at higher doses are possible to the condensed target without decreasing toxicity. ${ }^{4,5}$ APBI treats just the breast tissue around the lumpectomy cavity in as little as 1 to 5 days. Laboratory data suggest higher dose per fraction may also be more tumoricidal. ${ }^{6}$

If APBI were shown to be as safe and effective as conventional WB-XRT, normal breast tissue away from the lumpectomy cavity would potentially be spared the effects of WB-XRT, and the shorter treatment course might diminish the impact of treatment on patients' lives. Breast conservation therapy could become an even more appealing alternative to mastectomy. ${ }^{\text {? }}$

Despite the reasonable biologic rationale, initial results with APBI were disappointing. Breast tissue tolerated the higher radiation dose per fraction. But permissive entry criteria, inadequate surgery, or poor radiotherapy treatment planning, such as optional preoperative mammography, limited control over tumor size, no restriction over tumor-free surgical resection margins, and target planning based on scar location, contributed to ipsilateral breast tumor recurrence (IBTR) rates that were sometimes more than double those seen in randomized trials using lumpectomy and WB-XRT. ${ }^{8,9}$ In another early randomized trial exploring $\mathrm{PBI}$ (rather than $\mathrm{APBI}$ ) versus WB-XRT, more than twice as many IBTRs were seen in the PBI group than the WB-XRT group: however, target definition was inadequate here also, sometimes based on scar or patient recollection, with radiotherapy delivered 
Dirbas

without a defined treatment margin around the lumpectomy cavity. ${ }^{10}$

Subsequent studies with multicatheter interstitial brachytherapy (MIB) incorporating refinements in patient selection, surgical technique, and radiotherapy delivery led to the first encouraging results with APBI. ${ }^{11,12}$

MIB is now 1 of 4 radiotherapy methods for delivering APBI; the additional methods include intracavitary brachytherapy, intraoperative radiotherapy, and three-dimensional (3D) conformal radiotherapy. Some of these approaches bear additional subtechniques that can differ substantially. The vagaries of patient selection, surgical technique, and radiotherapy delivery pose a challenge to interpreting the existing literature, particularly when comparing one method or institutional experience with another. ${ }^{13}$

\section{Patient Selection}

\section{Pretreatment Imaging}

As with standard breast conservation therapy, diagnostic mammography and breast ultrasound, as indicated, are necessities for women considering APBI.

The role of breast MRI is less clear. Proponents suggest that MRI identifies otherwise occult lesions located away from the primary tumor, beyond the area of resection and radiotherapy, thereby potentially improving surgical treatment planning and reducing IBTR rates. Critics cite the historically low rates of recurrences after lumpectomy, high false-positive rates with breast MRI, uncertain biologic potential of otherwise "occult" findings in the breast, and recognition that even MRI can overlook both invasive and pre-invasive disease. Concern exists that MRI findings will benefit only a minority of patients.

To investigate the value of breast MRI as a screening tool for APBI, radiologists at Brigham and Women's Hospital retrospectively reviewed breast MRI scans from 79 women with core biopsy-proven breast cancer who seemed to be potential candidates for APBI. Nearly half the patients had MRI findings that would have led to questioning the suitability of APBI; 30 patients (38\%) had multifocal carcinoma, whereas 8 (10\%) had multicentric carcinoma. ${ }^{14} \mathrm{At}$ Stanford, MRI screening was found to exclude $10 \%$ of patients otherwise thought suitable for APBI, owing to more extensive in-breast disease and potential risk for an early IBTR. ${ }^{15}$ In the author's experience, MRI has been of greatest value in preparing for lumpectomy and intraoperative radiotherapy (IORT), when it is vital to gain the most knowledge of disease extent before surgical excision because radiotherapy is delivered before final margin status is available.

Overall, preoperative mammography and ultrasound should be performed as with standard breast conservation therapy. Breast MRI also should be performed, if clinically indicated. Outside the context of a clinical trial, the benefit and role of breast MRI preAPBI remains to be defined.

\section{Inclusion/Exclusion Criteria}

Early randomized trials evaluating standard breast conservation therapy required preoperative mammography, established upper limits on lesion size, required excision to tumor-free margins, and assessed adequacy of radiotherapy treatment planning. ${ }^{16,17}$ The first successful APBI studies from the Ochsner Clinic and William Beaumont Hospital established new benchmarks for this paradigm, later modified to create consensus guidelines for patient selection for APBI treatment by the American Brachytherapy Society (ABS) and the American Society of Breast Surgeons (ASBS; Table 1). Importantly, these criteria currently limit APBI study and treatment to women aged 45 to 50 years or older with small $(<3 \mathrm{~cm})$, node-negative cancers, ductal histology, and negative margins.

Some believe that these APBI selection criteria may be too restrictive and instead suggest that tumorfree resection margins and improved radiotherapy technique are more important factors in reducing IBTR. The phase III NSABP B39/RTOG 0413, for instance, is available to women aged 18 years or older,

\begin{tabular}{|lll|}
\hline \multicolumn{3}{|c|}{ Table 1} \\
& $\begin{array}{c}\text { Common Inclusion/Exclusion } \\
\text { Guidelines for APBI }\end{array}$ & ASBS $^{\dagger}$ \\
\hline Age & $>50 \mathrm{y}$ & $>45 \mathrm{y}$ \\
Size & $\leq 3 \mathrm{~cm}$ & $\leq 3 \mathrm{~cm}$ \\
Histology & IDC & IDC and/or DCIS \\
Margins & Negative & Negative \\
Lymph nodes & No & SN negative \\
\hline
\end{tabular}

Abbreviations: ABS, American Brachytherapy Society; APBI, accelerated partial breast irradiation; ASBS, American Society of Breast Surgeons; DCIS, ductal carcinoma in situ; IDC, invasive ductal carcinoma; SN, sentinal node.

*Revised February 2007

${ }^{\dagger}$ Revised October 2008 
Accelerated Partial Breast Irradiation

does not require unifocal disease, and permits patients with 1 to 3 positive axillary lymph nodes, provided no extracapsular extension is present.

Investigators at the University of Wisconsin applied the NSABP B39 study criteria to a retrospective cohort of 273 patients treated with APBI using either high dose rate (HDR) interstitial brachytherapy or MammoSite RTS catheter (Cytyc Corporation, a Hologic Company, Marlborough, Massachusetts). ${ }^{18}$ Patients were classified as having high-risk $(\mathrm{n}=90)$ or low-risk $(n=183)$ lesions. Those younger than 50 years, with tumors that were estrogen receptornegative or with involved nodes were deemed high risk, whereas all others were deemed low risk. With a median follow-up of 48.5 months, no significant difference was found, although the crude local recurrence rate was elevated in the high-risk group ( $4.4 \%$ vs. $2.2 \%$ ).

Emerging data are also exploring APBI in biologic subsets of breast cancer. A small, retrospective analysis of women with triple-negative tumors (estrogen receptor-, progesterone receptor-, and human epidermal growth factor receptor 2-negative) compared outcomes after either conventional WB-XRT or APBI using the MammoSite RTS catheter. At a median follow-up of 20.4 months, local control rates were $94.4 \%$ with WB-XRT and $100 \%$ with APBI. These pilot data suggest that triple-negative receptor status itself is not an obvious deterrent to APBI. ${ }^{19}$

Currently, optimal patient selection criteria, such as age, tumor histology, and lymph node status, are not clearly defined. These variables can vary widely among trials and should be an important focus as results of any APBI study are interpreted.

\section{Surgical Technique}

\section{Exclusion of Multifocal and/or Multicentric Disease, Excision to Tumor-Free Margins}

The breast surgeon plays an important role in APBI through ensuring areas of potential multifocal or multicentric disease are not overlooked, achieving excision of the lesion with tumor-free margins, minimizing volume loss or distortion of the breast geometry with the resection, adequately staging the axilla, and, in some forms of APBI (intracavitary brachytherapy, IORT, and 3D conformal radiotherapy), preparing the lumpectomy cavity margins for radiotherapy.

Among these surgical issues, ongoing controversy exists about what should define an optimal histologic tumor-free margin, whether for routine WB-XRT or APBI. ${ }^{20}$ Many surgeons and allied breast cancer specialists are comfortable with a nontransection, "no ink on tumor" model, as has been used with excellent long-term results in NSABP breast conservation trials. Other groups, however, believe wider tumor free-margins, most commonly 1 or 2 $\mathrm{mm}$, are desirable, if not necessary, to achieve optimal local control. Because of the limited radiation target volume and the potential impact of residual disease in the cavity wall, the definition of an adequate margin is potentially of even greater importance in women offered APBI. The vagaries of margin requirement in phase I, II, and III APBI trials pose a challenge, and careful retrospective work will be needed to gauge if adequate standards can be defined.

\section{Preparation of the Tumor Bed for APBI} Surgical Preparation for Intracavitary Brachytherapy: For patients receiving APBI with intracavitary brachytherapy using balloon-type devices, such as the MammoSite, surgeons must consider cavity size, cavity dimensions, and thickness of the breast parenchyma between the lumpectomy cavity surface and skin before the surgical procedure is complete. ${ }^{21}$ Conformance of balloon surface to cavity margins is critical. The benefit of a minimum 5- to 7-mm soft tissue separation between the balloon surface and skin has been shown in several studies: narrower separation is associated with poorer cosmetic results. ${ }^{22}$ (The need for a 5-7 mm tissue "buffer" may be less critical if APBI is delivered with one of the newer multicatheter intracavitary brachytherapy devices, described later, because they may provide greater control over dose distribution.) If cavity geometry conditions are not established properly at surgery, patients may not be able to receive APBI with an intracavitary device.

Initially, the MammoSite was commonly deployed at the time of lumpectomy. A "sizer" is now more typically placed in the breast at the conclusion of the lumpectomy to measure cavity volume. If the pathology results confirm patient suitability for APBI, the balloon catheter is inserted in the office. Delayed placement, usually 1 to 2 weeks after surgery, is associated with a lower rate of seroma formation..$^{23}$ Placement beyond 3 weeks can be difficult because of contraction and rigidity of the breast tissue surrounding the lumpectomy cavity. 
Dirbas

Surgical Preparation for Single Fraction Breast IORT: With single fraction breast IORT, surgeons perform the lumpectomy, mobilize surrounding breast tissue, reconstruct lumpectomy cavity margins to generate the optimal target for the IORT technique at hand, and then work with the radiation oncology team to guide placement of the IORT equipment. The most common methods for delivering IORT are the ELIOT (electron intraoperative radiotherapy technique) approach, which directs high-energy electrons to lumpectomy cavity margins through a collimator placed just inside the surgical incision, and the TARGIT (targeted intraoperative radiotherapy) approach which relies on a miniature electron generator that delivers low-energy radiation through a spherical applicator that is temporarily set within the lumpectomy cavity itself. The details of these approaches have been described previously. ${ }^{24,25}$ IORT warrants even greater attention to surgical technique than usual and close collaboration between surgical and radiation oncology teams.

Surgical Preparation for Three-Dimensional Conformal Radiotherapy: Minimizing lumpectomy cavity volume is extremely important with 3D conformal radiotherapy (3D-CRT). If the lumpectomy cavity and associated radiotherapy target volume are too large in relationship to the overall breast volume, the potential benefit of APBI diminishes and toxicity concerns increase. The NSABP B39 trial has specific constraints in this regard. ${ }^{26}$ Investigators have also shown significant interobserver variability in defining lumpectomy cavity margins even with experienced breast radiation oncologists. ${ }^{27}$ To minimize the possibility of errors in defining the lumpectomy cavity for patients considered candidates for 3D-CRT, surgeons are advised to place metal clips in the cavity margins that are visible on the postoperative CT scan used for radiotherapy treatment planning and delivery. ${ }^{28,29}$

\section{Radiotherapy Technique for APBI}

APBI has 4 general approaches (Table 2), each having benefits and limitations. This section reviews recent clinical trial results with each.

\section{Interstitial Brachytherapy}

MIB is now most commonly performed using a series of thin, hollow catheters (often in the range of 12-16 catheters) deployed through the full thickness of the breast tissue parallel to each other around the lumpectomy cavity. After CT-based treatment planning is complete, a single ${ }^{192} \mathrm{Ir}$ seed is then sequentially placed by an HDR afterloader at different dwell positions in each catheter. Several hundred dwell positions are possible this way, with the radioactive seed stopping at each dwell point for a variable amount of time. This technique in many ways provides the most exquisite control over delivery of radiation around the lumpectomy cavity. Early studies with MIB are followed with great interest because some of these trials provide the longest clinical follow-up with APBI currently available.

RTOG 9517, a multicenter, MIB, APBI study permitting either low dose rate (LDR) or HDR radiation sources, enrolled 99 patients. Through 6.14 years of median follow-up, the IBTR rate is $6 \%$ with LDR and 3\% with HDR. The regional recurrence rate was $0 \%$ with LDR and 5\% with HDR. These results substantiated institutional studies that suggested MIB could produce results approaching or equaling those seen with WB-XRT. ${ }^{30}$

Low rates of local recurrence ( $6 \%$ at 5 years) have also been reported from Tufts New England Medical Center for MIB. ${ }^{31}$ This group further noted that subcutaneous toxicity worsened with time owing to fat necrosis in more than half of the cohort. Other centers have noted wound healing difficulties in approximately $5 \%$ of patients and fat necrosis requiring reoperation in $4 \% .{ }^{32}$ Additional complications noted with MIB include rib fractures and suboptimal cosmetic results in patients undergoing interstitial brachytherapy and anthracycline-based chemotherapy. ${ }^{33}$ Some of these side effects are from the unavoidable "hot spots" immediately surrounding the dwell positions of the radiation source used with MIB.

As follow-up with MIB progresses, results from these phase I/II studies continue to suggest acceptable local toxicity and effective local control. The single phase III trial that has published outcomes results used MIB as the primary accelerated radiotherapy modality (discussed later). Results compared favorably with the control WB-XRT group.

\section{Interstitial Brachytherapy Derivatives (Balloon Brachytherapy, Single-Entry Multicatheter Brachytherapy)}

The appeal of APBI combined with the limited availability of MIB stimulated development of alternative solutions. The first derivative, the MammoSite, 
Accelerated Partial Breast Irradiation

\begin{tabular}{|c|c|c|c|c|}
\hline & $\begin{array}{l}\text { Interstitital } \\
\text { Brachytherapy }\end{array}$ & $\begin{array}{l}\text { Intracavitary } \\
\text { Brachytherapy }\end{array}$ & $\begin{array}{l}\text { Intraoperative } \\
\text { Radiotherapy }\end{array}$ & $\begin{array}{l}\text { 3D Conformal } \\
\text { Radiotherapy }\end{array}$ \\
\hline $\begin{array}{l}\text { Methods (see } \\
\text { text for } \\
\text { variations) }\end{array}$ & $\begin{array}{l}\text { Series of parallel } \\
\text { catheters inserted } \\
\text { through-and-through } \\
\text { breast tissue } \\
\text { surrounding } \\
\text { lumpectomy cavity; } \\
\text { radioactive seed } \\
\text { deployed sequentially } \\
\text { by HDR afterloading } \\
\text { machine to hundreds } \\
\text { of dwell positions }\end{array}$ & $\begin{array}{l}\text { Balloon catheter or } \\
\text { other device inserted } \\
\text { percutaneously to center of } \\
\text { lumpectomy cavity; } \\
\text { radioactive seed deployed } \\
\text { to balloon center using HDR } \\
\text { afterloading machine to } 1 \\
\text { or multiple dwell positions }\end{array}$ & $\begin{array}{l}\text { Immediately after } \\
\text { lumpectomy, breast } \\
\text { tissue near cavity is } \\
\text { mobilized; } \\
\text { target volume may be } \\
\text { formed by apposing } \\
\text { cavity margins, which are } \\
\text { targeted through a } \\
\text { cylindrical collimator, or } \\
\text { by conforming cavity } \\
\text { margins to spherical } \\
\text { applicator }\end{array}$ & $\begin{array}{l}\text { Multiple external } \\
\text { beam (usually } \\
4 \text { to } 5 \text { ) mini- } \\
\text { tangents are } \\
\text { targeted at } \\
\text { lumpectomy } \\
\text { cavity and } \\
\text { margin }\end{array}$ \\
\hline Dose & $\begin{array}{l}34 \text { Gy delivered in } \\
10 \text { doses over } 5 \text { days }\end{array}$ & $\begin{array}{l}34 \text { Gy delivered in } 10 \text { doses } \\
\text { over } 5 \text { days }\end{array}$ & $\begin{array}{l}20 \text { to } 21 \text { Gy delivered in } \\
\text { single dose, } \\
\text { technique-dependent }\end{array}$ & $\begin{array}{l}38.5 \text { Gy delivered } \\
\text { in } 10 \text { doses over } \\
5 \text { days }\end{array}$ \\
\hline Target volume & $\begin{array}{l}1.5-\mathrm{cm} \text { margin around } \\
\text { lumpectomy cavity }\end{array}$ & $\begin{array}{l}\text { 1-cm margin around } \\
\text { lumpectomy cavity }\end{array}$ & $\begin{array}{l}1-\text { to } 3-\mathrm{cm} \text { margin around } \\
\text { lumpectomy cavity }\end{array}$ & $\begin{array}{l}2.5-\mathrm{cm} \text { margin } \\
\text { around } \\
\text { lumpectomy cavity }\end{array}$ \\
\hline $\begin{array}{l}\text { Target } \\
\text { confirmation }\end{array}$ & CT-based & CT-based & $\begin{array}{l}\text { Visual by surgeon and } \\
\text { radiation oncologist in } \\
\text { operating room }\end{array}$ & CT-based \\
\hline Timing & $\begin{array}{l}\text { After pathology results, } \\
\text { usually within } 2 \text { months } \\
\text { of surgery }\end{array}$ & $\begin{array}{l}\text { After pathology results, } \\
\text { usually within } 3 \text { weeks of } \\
\text { surgery }\end{array}$ & $\begin{array}{l}\text { Immediately after surgery } \\
\text { in the operating room }\end{array}$ & $\begin{array}{l}\text { After pathology } \\
\text { results, usually } \\
\text { within } 2 \text { months of } \\
\text { surgery }\end{array}$ \\
\hline Strengths & $\begin{array}{l}\text { Hundreds of dwell } \\
\text { positions for radioactive } \\
\text { seed within breast; } \\
\text { may be best for } \\
\text { irregularly shaped } \\
\text { lumpectomy cavity }\end{array}$ & $\begin{array}{l}\text { Ease of device placement, } \\
\text { availability of device, rapid } \\
\text { learning curve, straightforward } \\
\text { radiotherapy treatment } \\
\text { planning; good for } \\
\text { symmetric lumpectomy } \\
\text { cavity, deeper in breast } \\
\text { tissue }\end{array}$ & $\begin{array}{l}\text { Single radiation dose, } \\
\text { spares skin, muscle, } \\
\text { surrounding breast tissue } \\
\text { to greatest degree; } \\
\text { no postoperative } \\
\text { radiation treatments } \\
\text { Best for tumors that can } \\
\text { be excised to tumor-free } \\
\text { margins with high degree } \\
\text { of confidence }\end{array}$ & $\begin{array}{l}\text { Can often be } \\
\text { delivered using } \\
\text { same radiotherapy } \\
\text { machines as for } \\
\text { WB-XRT; no need } \\
\text { for postoperative } \\
\text { device insertion; } \\
\text { better when } \\
\text { lumpectomy cavity } \\
\text { represents small } \\
\text { percentage of } \\
\text { breast volume, } \\
\text { patient reluctant } \\
\text { to undergo } \\
\text { placement of } \\
\text { catheter(s) for APBI }\end{array}$ \\
\hline Limitations & $\begin{array}{l}\text { Additional procedure } \\
\text { customary for catheter } \\
\text { placement during } \\
\text { post-op period; } \\
\text { dose inhomogeneity } \\
\text { due to "hot spots" } \\
\text { around radioactive seed; } \\
\text { presently available only } \\
\text { in specialized centers }\end{array}$ & $\begin{array}{l}\text { Cost of device; separate } \\
\text { procedure is now customary } \\
\text { for catheter placement; } \\
\text { fewer dwell positions } \\
\text { compared with interstitial } \\
\text { brachytherapy }\end{array}$ & $\begin{array}{l}\text { Treatment is delivered } \\
\text { before final pathology } \\
\text { results are available; } \\
\text { uncertain long-term tissue } \\
\text { tolerance for single, large } \\
\text { radiation dose; } \\
\text { presently available only in } \\
\text { specialized centers }\end{array}$ & $\begin{array}{l}\text { Need to expand } \\
\text { radiation field to } \\
\text { account for } \\
\text { respiration and } \\
\text { daily setup } \\
\text { variation; } \\
\text { larger target } \\
\text { volume } \\
\text { responsible for } \\
\text { greater irradiation } \\
\text { of surrounding } \\
\text { breast tissue }\end{array}$ \\
\hline
\end{tabular}

Abbreviations: $\mathrm{APBI}$, accelerated partial breast irradiation; HDR, high dose rate. 
contains a channel to the balloon center through which an ${ }^{192}$ Ir seed can be placed to deliver APBI.

The pilot study with the MammoSite, which enrolled 43 women, has shown no ipsilateral recurrences in the 36 treated women available for long-term outcomes who have been followed up for a median of 5.5 years, although an infection rate of $9 \%$ was observed. ${ }^{34}$ Skin spacing of $7 \mathrm{~mm}$ or greater between the device surface and skin improved cosmetic results.

The William Beaumont Hospital single-institution experience with 80 patients noted a 3-year actuarial recurrence rate of $3 \%$ and advised skin spacing greater than $7 \mathrm{~mm} .{ }^{35}$ Cosmetic outcome was diminished in patients who underwent adjuvant chemotherapy.

A multiinstitutional trial with the MammoSite system studied 483 patients and reported 10 IBTRs, with 6 near the lumpectomy site and 4 elsewhere in the breast, after a median follow-up of 24 months. The overall infection rate was $9 \%$, which dropped to $5 \%$ when the device was placed postoperatively. Skin spacing less than $6 \mathrm{~mm}$ increased the risk for severe acute skin reaction. Based on these findings, the investigators recommended prophylactic antibiotics, closedcavity placement postoperatively, multiple dwell positions for the HDR source within the balloon, and a minimum skin spacing of $6 \mathrm{~mm} \cdot{ }^{36}$

An ASBS registry of MammoSite use has tracked 1440 patients with a median tumor size of $10 \mathrm{~mm}$, including $13 \%$ with pure ductal carcinoma in situ. ${ }^{37}$ Physician registration of patients to the log was discretionary. The 2-year actuarial IBTR rate is $1.6 \%$; 6 patients $(0.4 \%)$ had axillary failures. Other findings from this registry include radiation recall in 9 of 50 patients (18\%) when chemotherapy was given less than 3 weeks after radiotherapy but only in 6 of 81 patients (7.4\%) when given more than 3 weeks after radiotherapy. Superior cosmetic results were found in women who underwent chemotherapy more than 3 weeks after completion of radiation. ${ }^{38}$

A similar catheter design to the MammoSite system is the Axxent balloon catheter (Xoft, Inc., Sunnyvale, California). However, rather than using ${ }^{192} \mathrm{Ir}$ or other isotopes as the radiation source, the Axxent system uses a miniaturized electronic x-ray source powered from a standard wall outlet and with a rapid dose fall-off that does not require room shielding. Treatment planning with this device is in its early development stages. ${ }^{39}$ Grade 3 toxicities seen in the pilot study included skin reactions, such as blistering or erythema in 3 patients and breast pain in 2 .

A potential limitation of these systems is the proximity of the balloon/lumpectomy interface to the skin or chest wall, because there is limited ability for asymmetric delivery of irradiation with a single central channel. To work around this limitation, newer single-entry, multicatheter intracavity brachytherapy devices have been developed that allow a greater number of dwell positions for the HDR source (still typically an ${ }^{192} \mathrm{Ir}$ seed) within the lumpectomy cavity. Two devices, the Savi (Cianna Medical, Inc., Aliso Viejo, California) and Contura (SenRx, Inc., Aliso Viejo, California), have been used in clinical trials with another, the ClearPath (North American Scientific, Chatsworth, California), currently in development. One goal of these innovations is to increase the candidacy of patients for intracavitary brachytherapy and APBI.

Data from phase I/II studies predominantly using the MammoSite for intracavitary brachytherapy suggest that local toxicity and effectiveness can be achieved comparable to that seen with interstitial brachytherapy and historical controls.

Apart from clinical issues, concern has been publicly expressed recently about reimbursements and the rapidity of adopting the MammoSite outside the context of clinical trials (Cytyc reports 32,000 devices implanted, whereas The New York Times reports 45,000)..$^{40,41}$ The desire for Medicare to stimulate adoption of promising technology through reimbursement is understandable. It is difficult, if not impossible, to assess to what degree use of the MammoSite is attributable to reimbursement alone versus physician enthusiasm over helping patients complete radiotherapy in 5 days rather than 6 weeks. ${ }^{42}$ Satisfactory early toxicity and effectiveness profiles in phase I/II studies with interstitial brachytherapy and the MammoSite, as noted previously, support the enthusiasts' perspective, but do not guarantee that all patients treated with the device outside of a trial met optimal criteria for APBI, will have adequate clinical follow-up, or underwent a treatment (i.e., intracavitary brachytherapy) that will ultimately be validated by a phase III study. ${ }^{9,11}$ The ABS, ASBS, and American Society of Breast Disease, among others (and this author), have all been early, strong proponents of clinical trial enrollment for this and other forms of APBI because of 
both the scientific knowledge that is generated and the multiple associated benefits clinical trials bring to patients and clinicians.

\section{IORT}

IORT has the potential advantage of sparing normal surrounding tissue to a greater degree than other APBI methods while delivering the entire therapeutic dose in a single fraction while the patient is still under anesthesia at the time of breast surgery. ${ }^{43}$ Two European centers, the University College Hospital (UCH) in London and the European Institute of Oncology (EIO) in Milan, have each developed particular approaches to IORT called TARGIT and ELIOT, respectively.

For the TARGIT trial, IORT is delivered using the Intrabeam Photon Radiotherapy System (Zeiss Inc., Oberkochen, Germany), a device with a $50 \mathrm{kV}$ energy source contained with a spherical applicator that is placed within the lumpectomy cavity after tumor excision. With the most common applicator size, the delivered dose is $20 \mathrm{~Gy}$ at a distance of $2 \mathrm{~mm}$ from the applicator surface, which falls off to 5 Gy at $1 \mathrm{~cm} .{ }^{44}$ Because of the rapid dose fall-off, shielding requirements are less than for some other forms of APBI. For these same reasons, critics have expressed concern that the entire target volume does not fully receive a therapeutic dose of radiation. The phase III TARGIT trial includes institutions from Europe, Australia, and the United States.

The ELIOT approach also delivers IORT immediately after quadrantectomy. The breast tissue immediately surrounding the lumpectomy cavity is dissected free from overlying skin anteriorly and the pectoralis muscle posteriorly, giving mobility to the lumpectomy cavity margins. Lead and aluminum disks are then placed through the open incision on the pectoralis as a beam stopper, followed by suture approximation of the lumpectomy cavity edges to each other as the lumpectomy cavity is temporarily obliterated. This creates a target volume of resection cavity margins overlying the beam stopper. Skin edges are then retracted and a cylindrical collimator is placed within the incision overlying the target volume. A linear accelerator is then docked to the collimator and $21 \mathrm{~Gy}$ delivered to the $90 \%$ isodose line using high-energy electrons directed to the target volume. The radiotherapy apparatus is removed, sutures approximating cavity margins are cut, the beam stopper is removed, and the procedure is completed. ${ }^{45}$ The patient receives no further radiotherapy.
In a phase III study, the EIO randomized 1306 women to either IORT or WB-XRT. Results from the phase III study are pending. A separate cohort of 1246 patients received IORT outside the context of the randomized trial, either because the patients were part of their pilot IORT study, had refused randomization, or did not meet inclusion/exclusion criteria. ${ }^{46}$ At a median follow-up of 26 months, a total of 41 recurrences were seen in the affected breast, for a crude IBTR rate of $3.3 \%$. In this cohort, 40 patients $(3.2 \%)$ developed mild fibrosis, whereas $6(.5 \%)$ developed severe fibrosis. The group also reported a condition they named liponecrosis in 58 patients (4.7\%), which is described as a self-limited condition in most patients manifested by skin erythema and brown fluid within the lumpectomy cavity, usually not requiring intervention. A separate, multiinstitutional, phase III trial with ELIOT is also underway in Rome based on the Milan EIO approach. ${ }^{47}$

Additional groups are exploring other methods for single-fraction IORT using intraoperative HDR brachytherapy, collimator-based IORT after lumpectomy (as opposed to quadrantectomy), and in situ IORT. ${ }^{48-50}$

The limited data available from the IORT trials suggest results comparable to those seen with APBI using brachytherapy and to historical controls with WB-XRT. Longer follow-up will show whether results can be replicated at different institutions, whether lack of margin results before radiation is problematic, and whether the single large dose of radiotherapy is associated with excessive tissue fibrosis at late follow-up, a longstanding concern of IORT critics.

\section{D-CRT}

3D-CRT is a variation on standard WB-XRT in that external beams are targeted at the breast, though several beams are used and the target is the lumpectomy cavity and margins rather than the whole breast. ${ }^{51}$ As with the original, successful interstitial brachytherapy studies, the primary target is approximately a $1.5-\mathrm{cm}$ margin around the lumpectomy cavity with an additional $0.5 \mathrm{~cm}$ width for daily setup variation and another $0.5 \mathrm{~cm}$ width for respiratory variation. In a pilot study with this technique, the Beaumont group included patients with invasive lobular carcinoma, pure ductal carcinoma in situ, up to 3 involved axillary nodes, and a recommendation, rather than requirement, for tumor-free margins of $2 \mathrm{~mm}$ or larger. ${ }^{52}$ 
Dirbas

Preliminary experience with this new radiotherapy method suggests good cosmetic results.

Based on successful preliminary single-institution results, the RTOG sponsored a multiinstitutional 3DCRT trial, RTOG 0319. Recently reported results on 58 patients enrolled from August 2003 to April 2004 with a median follow-up of 3.5 years showed an IBTR rate of $6 \%$ overall, including $4 \%$ around the lumpectomy cavity..$^{53}$ Although the IBTR rate is higher than one might anticipate at this point, the study population is small.

An interesting twist on supine 3D-CRT APBI is to provide it in the prone position. This approach potentially helps minimize cardiac and pulmonary exposure to radiotherapy. This approach has been used in a pilot study of 47 patients who received a total dose of $30 \mathrm{~Gy}$ in 5 fractions over 10 days. At a median follow-up of 18 months, no IBTRs were reported..$^{54}$

Given that 3D-CRT is most similar in technique to existing WB-XRT, this form of partial breast radiotherapy will likely be used with increasing frequency despite being the latest major entry into the APBI arena. In addition to efficacy, one of the more important questions regarding 3D-CRT will be local toxicity because this method treats a broader volume of the breast tissue than other APBI approaches.

\section{Phase III Trials}

No fewer than 8 prospective randomized trials are currently studying APBI (Table 3). ${ }^{47,55-60}$ None of the current trials have identical inclusion/exclusion criteria. Margin requirements vary among the studies. Each is heavily weighted, intentionally or unintentionally, to some extent towards evaluation of a particular APBI technique versus whole breast irradiation. None of the studies directly compares one form of accelerated radiotherapy with another. Of these trials, 6 continue to accrue patients, 2 have completed accrual, and only 1 has reported oncology outcomes (Table 3 ). The National Institute of Oncology in Hungary randomized 248 women to WB-XRT or APBI, primarily consisting of HDR interstitial brachytherapy. Results showed $4.7 \%$ and $3.4 \% 5$-year actuarial rates of local recurrence rates in the APBI and WB-XRT arms, respectively $(P=$ not significant $)$. Symptomatic and asymptomatic fat necrosis was comparable in both groups. Cosmesis was reported to be better with APBI..$^{55}$
The NSABP B39/RTOG 0413 study is the largest phase III APBI trial underway, with a planned accrual of 4300 patients. It is also the most complex study, in that patients are randomized to WB-XRT or PBI, with the choice of APBI technique at the discretion of the treating medical team and patient. The APBI options include interstitial brachytherapy, intracavitary brachytherapy with the MammoSite, and 3D-CRT. The study has met $75 \%$ of its accrual goal (Wapnir I, personal communication, 2008). Accrual of low-risk patients has closed to encourage participation of patients at higher risk (e.g., positive nodes, premenopausal status). A potential difficulty with this study is the likely imbalance of patients treated with various techniques within the $\mathrm{APBI}$ arm and the inability based on trial design to detect differences between the various techniques.

When long-term follow-up is available, some, all, or none of these phase III trials may show that APBI is a safe, effective alternative to conventional WBXRT. The success of any one approach must be considered in light of all aspects of treatment delivery, including patient selection, surgical technique, and accelerated radiotherapy method, and after review of all major outcomes, such as short- and long-term toxicity and effectiveness (especially IBTR rate, but also regional nodal recurrence). Based on results from previous studies, survival differences are unlikely to be seen. ${ }^{9}$

Given the variations within and among these trials, unless all studies show comparable results between APBI and WB-XRT, extrapolation from one approach to another may be challenging. Holding patient selection and surgical technique (such as margins) constant with a successful overall APBI approach will not provide implicit assurance that the accelerated radiotherapy technique used may be simply switched to radiotherapy technique, nor does success with a particular accelerated radiotherapy technique guarantee that the same results would be seen if surgical technique or patient selection were altered, and so on. Because enough variability exists between these trials, important observations on various aspects of treatment delivery should be possible. Variations in toxicity and effectiveness could generate much discussion on patient selection and treatment variables as trial results emerge. 
Accelerated Partial Breast Irradiation

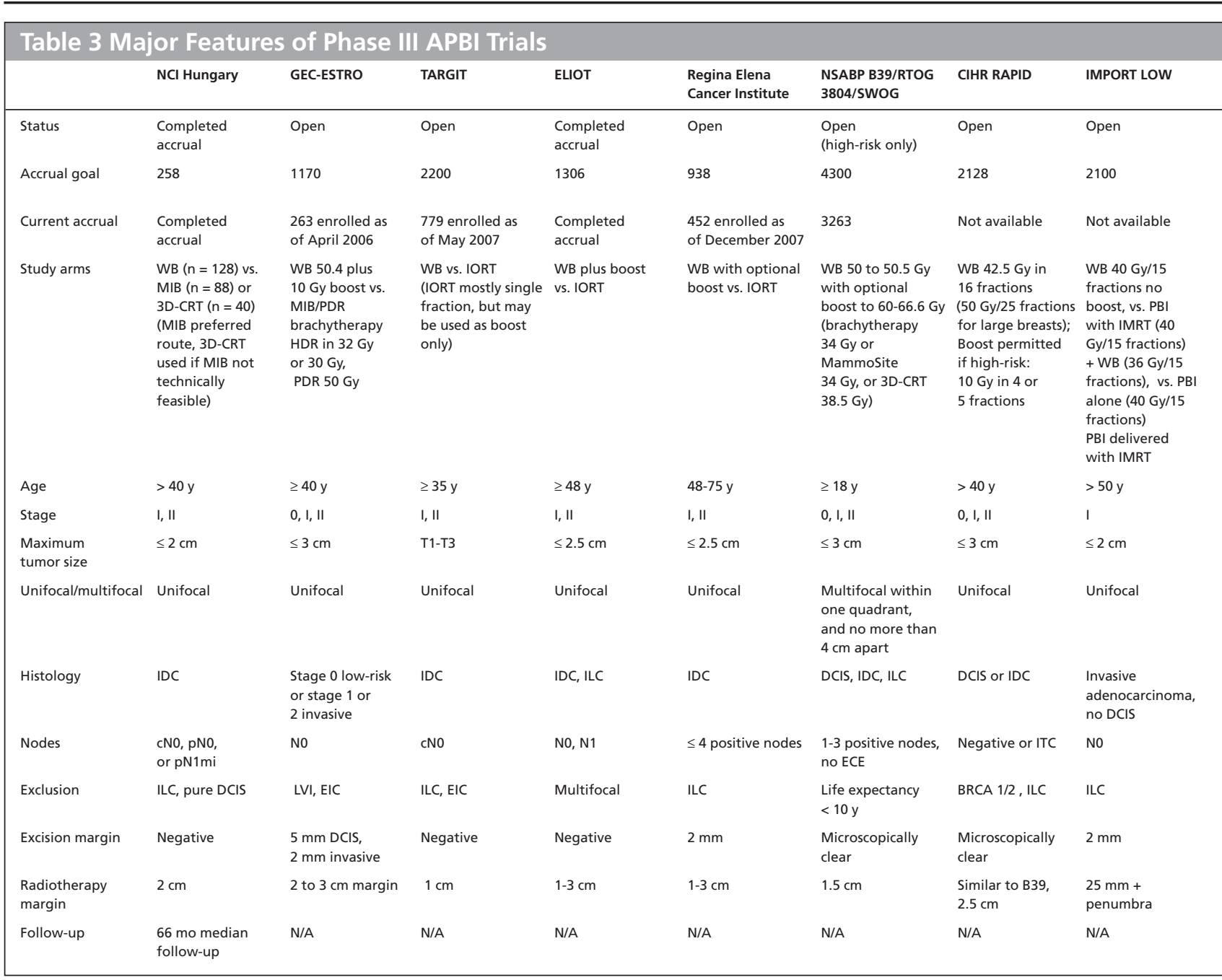

Abbreviations: 3D-CRT, 3-dimensional conformal radiotherapy; CIHR RAPID, Canadian Institutes of Health Research Radiation Therapy for Accelerated Partial Breast Irradiation Trial; DCIS, ductal carcinoma in situ; ECE, extracapsular extension; EIC, extensive intraductal carcinoma (DCIS); ELIOT, electron intraoperative radiotherapy technique; GEC-ESTRO, Groupe Européen de Curiethérapie and European Society for Therapeutic Radiology and Oncology; HDR, high dose rate; IDC, invasive ductal carcinoma; ILC, invasive lobular carcinoma; IMRT, intensity modulated radiotherapy; IMPORT LOW, intensity modulated and partial organ radiotherapy trial; IORT, intraoperative radiotherapy; ITC, isolated tumor cells; LVI, lymphovascular invasion; mi, micrometastasis; MIB, multicathether interstitial brachytherapy; N/A, not applicable; NCI, National Cancer Institute; PDR, pulsed dose rate; TARGIT, targeted intraoperative radiotherapy; WB, whole breast radiotherapy.

\section{Conclusions}

There is considerable interest in the use of APBI in breast conservation therapy. Early trials yielded disappointing outcomes. Significant changes in patient selection, surgical technique, and radiotherapy treatment planning have been adopted with promising initial results. Most available APBI data are from past and ongoing phase I/II studies. Only 1 phase III trial incorporating current treatment standards has begun to report early toxicity and outcomes data, with no significant difference seen between WB-XRT and APBI; 7 other trials have not yet begun reporting. Therefore, it is premature to declare that APBI is a standard treatment option for early-stage breast cancer. Patient selection, surgical technique, and radiotherapy treatment methods will likely remain key elements as this story unfolds. Currently, it is best to enroll patients in ongoing clinical trials to help further the understanding of APBI and offer patients the safest, most effective treatment options possible. 
Dirbas

\section{References}

1. Fisher B, Anderson S, Bryant J, et al. Twenty-year follow-up of a randomized trial comparing total mastectomy, lumpectomy, and lumpectomy plus irradiation for the treatment of invasive breast cancer. N Engl J Med 2002;347:1233-1241.

2. Veronesi U, Cascinelli N, Mariani L, et al. Twenty-year follow-up of a randomized study comparing breast-conserving surgery with radical mastectomy for early breast cancer. N Engl J Med 2002;347:1227-1232.

3. Whelan T, MacKenzie R, Julian J, et al. Randomized trial of breast irradiation schedules after lumpectomy for women with lymph nodenegative breast cancer. J Natl Cancer Inst 2002;94:1143-1150.

4. Recht A, Silver B, Schnitt S, et al. Breast relapse following primary radiation therapy for early breast cancer. I. Classification, frequency and salvage. Int J Radiat Oncol Biol Phys 1985;11:1271-1276.

5. Timmerman R, Bastasch M, Saha D, et al. Optimizing dose and fractionation for stereotactic body radiation therapy. Normal tissue and tumor control effects with large dose per fraction. Front Radiat Ther Oncol 2007;40:352-365.

6. Garcia-Barros M, Paris F, Codon-Cardo C, et al. Tumor response to radiotherapy regulated by endothelial cell apoptosis. Science 2003;300:1155-1159.

7. Rose C, Recht A. Accelerated partial-breast irradiation (APBI): let's give it a good test. Int J Radiat Oncol Biol Phys 2003;57:1217-1218.

8. Fentiman IS, Poole $\mathrm{C}$, Tong $\mathrm{D}$, et al. Iridium implant treatment without external radiotherapy for operable breast cancer: a pilot study. Eur J Cancer 1991;27:447-450.

9. Ribeiro GG, Magee B, Swindell R, et al. The Christie Hospital breast conservation trial: an update at 8 years from inception. Clin Oncol (R Coll Radiol) 1993;5:278-283.

10. Dodwell DJ, Dyker K, Brown J, et al. A randomised study of wholebreast vs tumour-bed irradiation after local excision and axillary dissection for early breast cancer. Clin Oncol (R Coll Radiol) 2005; 17:618-622.

11. Vicini F, Kini VR, Chen $P$, et al. Irradiation of the tumor bed alone after lumpectomy in selected patients with early-stage breast cancer treated with breast conserving therapy. J Surg Oncol 1999;70:33-40.

12. King TA, Bolton JS, Kuske RR, et al. Long-term results of wide-field brachytherapy as the sole method of radiation therapy after segmental mastectomy for T(is,1,2) breast cancer. Am J Surg 2000;180:299_ 304.

13. Dirbas FM, Jeffrey SS, Goffinet DR. The evolution of accelerated, partial breast irradiation as a potential treatment option for women with newly diagnosed breast cancer considering breast conservation. Cancer Biother Radiopharm 2004;19:673-705.

14. Godinez J, Gombos EC, Chikarmane SA, et al. Breast MRI in the evaluation of eligibility for accelerated partial breast irradiation. AJR Am J Roentgenol 2008;191:272-277.

15. Horst KC, Ikeda DM, Birdwell RL, et al. Breast magnetic resonance imaging alters patient selection for accelerated, partial breast irradiation. Proceedings of the American Society for Therapeutic Radiology and Oncology 47th Annual Meeting 2005;63(Suppl 1):S4-5.

16. Fisher B, Redmond C, Poisson R, et al. Eight-year results of a randomized clinical trial comparing total mastectomy and lumpectomy with or without irradiation in the treatment of breast cancer. N Engl J Med 1989;320:822-828.

17. Veronesi U, Salvadori B, Luini A, et al. Conservative treatment of early breast cancer. Long-term results of 1232 cases treated with quadrantectomy, axillary dissection, and radiotherapy. Ann Surg 1990;211:250-259.
18. Patel RR, Christensen ME, Hodge CW, et al. Clinical outcome analysis in "high-risk" versus "low-risk" patients eligible for national surgical adjuvant breast and bowel B-39/radiation therapy oncology group 0413 trial: five-year results. Int J Radiat Oncol Biol Phys 2008;70:970-973.

19. Mohideen N, Nigh S, Lobo M, et al. Are patients with triple negative breast cancer appropriately treated with accelerated partial breast irradiation (APBI)? Proceedings of the American Society for Therapeutic Radiology and Oncology 47th Annual Meeting 2008; 72(1 Suppl 1):S198.

20. Singletary SE. Surgical margins in patients with early-stage breast cancer treated with breast conservation therapy. Am J Surg 2002; 184:383-393.

21. Zannis V, Beitsch P, Vicini F, et al. Descriptions and outcomes of insertion techniques of a breast brachytherapy balloon catheter in 1403 patients enrolled in the American Society of Breast Surgeons MammoSite breast brachytherapy registry trial. Am J Surg 2005; 190:530-538.

22. Vicini FA, Beitsch PD, Quiet CA, et al. First analysis of patient demographics, technical reproducibility, cosmesis, and early toxicity: results of the American Society of Breast Surgeons MammoSite breast brachytherapy trial. Cancer 2005;104:1138-1148.

23. Benitez PR, Chen PY, Vicini FA, et al. Partial breast irradiation in breast conserving therapy by way of interstitial brachytherapy. Am J Surg 2004;188:355-364.

24. Intra M, Luini A, Gatti G, et al. Surgical technique of intraoperative radiation therapy with electrons (ELIOT) in breast cancer: a lesson learned by over 1000 procedures. Surgery 2006;140:467471.

25. Vaidya J, Baum M, Tobias JS, et al. The novel technique of delivering targeted intraoperative radiotherapy (Targit) for early breast cancer. Eur J Surg Oncol 2002;28:447-454.

26. NSABP B39/RTOG 0413 Protocol. Available at: http://www.rtog. org/members/protocols/0413/0413.pdf. Accessed January 2, 2009.

27. Landis DM, Luo W, Song J, et al. Variability among breast radiation oncologists in delineation of the postsurgical lumpectomy cavity. Int J Radiat Oncol Biol Phys 2007;67:1299-1308.

28. Dzhugashvili M, Dunant $A$, Pichenot $C$, et al. The added value of surgical clips in target volume determination in accelerated partial breast cancer irradiation. Proceedings of the American Society for Therapeutic Radiology and Oncology 47th Annual Meeting 2008;72(1 Suppl 1):S173.

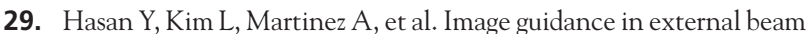
accelerated partial breast irradiation: comparison of surrogates for the lumpectomy cavity. Int J Radiat Oncol Biol Phys 2008;70:619-625.

30. Arthur DW, Winter K, Kuske RR, et al. A phase II trial of brachytherapy alone after lumpectomy for select breast cancer: tumor control and survival outcomes of RTOG 95-17. Int J Radiat Oncol Biol Phys 2008;72:467-473.

31. Kaufman SA, DiPetrillo TA, Price LL, et al. Long-term outcome and toxicity in a Phase I/II trial using high-dose-rate multicatheter interstitial brachytherapy for T1/T2 breast cancer. Brachytherapy 2007;6:286-292.

32. Anderson PJ, Mark R, Neumann $T$, et al. Interstitial high dose rate (HDR) brachytherapy for early stage breast cancer: five year followup of 168 cases using multi-catheter technique. Proceedings of the American Society for Therapeutic Radiology and Oncology 47th Annual Meeting 2008;72(1 Suppl 1):S517.

33. Yoshida K, Nose T, Masuda N, et al. Preliminary result of accelerated partial breast irradiation after breast-conserving surgery. Breast Cancer 2008; in press. 
Accelerated Partial Breast Irradiation

34. Benitez PR, Keisch ME, Vicini F, et al. Five-year results: the initial clinical trial of MammoSite balloon brachytherapy for partial breast irradiation in early-stage breast cancer. Am J Surg 2007;194:456-462.

35. Chao KK, Vicini FA, Wallace M, et al. Analysis of treatment efficacy, cosmesis, and toxicity using the MammoSite breast brachytherapy catheter to deliver accelerated partial-breast irradiation: the William Beaumont Hospital experience. Int J Radiat Oncol Biol Phys 2007;69:32-40.

36. Cuttino LW, Keisch M, Jenrette JM, et al. Multi-institutional experience using the MammoSite radiation therapy system in the treatment of early-stage breast cancer: 2-year results. Int J Radiat Oncol Biol Phys 2008;71:107-114.

37. Vicini F, Beitsch PD, Quiet CA, et al. Three-year analysis of treatment efficacy, cosmesis, and toxicity by the American Society of Breast Surgeons MammoSite Breast Brachytherapy Registry Trial in patients treated with accelerated partial breast irradiation (APBI). Cancer 2008;112:758-766.

38. Haffty BG, Vicini FA, Beitsch P, et al. Timing of chemotherapy after mammosite radiation therapy system breast brachytherapy: analysis of the American Society of Breast Surgeons MammoSite Breast Brachytherapy Registry Trial. Int J Radiat Oncol Biol Phys 2008; 72:1441-1448.

39. Dickler A, Kirk MC, Seif N, et al. A dosimetric comparison of MammoSite high-dose-rate brachytherapy and Xoft Axxent electronic brachytherapy. Brachytherapy 2007;6:164-168.

40. MammoSite Web site. Available at: http://www.mammosite.com/ breast-lumpectomy/whatis-mammosite.cfm. Accessed December 15, 2008.

41. Abelson R. Quickly vetted, treatment is offered to patients. The New York Times. October 26, 2008:A1.

42. Suh WW, Pierce LJ, Vicini FA, Hayman JA, et al. A cost comparison analysis of partial versus whole-breast irradiation after breast-conserving surgery for early-stage breast cancer. Int J Radiat Oncol Biol Phys 2005;62:790-796

43. Nairz O, Deutschmann $\mathrm{H}$, Kopp $\mathrm{M}$, et al. [A dosimetric comparison of IORT techniques in limited-stage breast cancer]. Strahlenther Onkol 2006;182:342-348 [in German].

44. Vaidya JS, Baum M, Tobias JS, et al. Targeted intra-operative radiotherapy (Targit): an innovative method of treatment for early breast cancer. Ann Oncol 2001;12:1075-1080.

45. Gatzemeier W, Orecchia R, Gatti G, et al. [Intraoperative radiotherapy (IORT) in treatment of breast carcinoma- a new therapeutic alternative within the scope of breast-saving therapy? Current status and future prospects. Report of experiences from the European Institute of Oncology (EIO), Mailand]. Strahlenther Onkol 2001; 177:330-337 [in German].

46. Veronesi U, Orecchia R, Luini A, et al. Full dose intraoperative radiotherapy with electrons (ELIOT) during breast conserving surgery-experience with 1246 cases. Available at: http://www. ecancermedicalscience.com/view-responses.asp?doi=10.3332/ eCMS.2008.65. Accessed December 15, 2008.
47. Arcangeli G. IOERT vs. EBRT in breast cancer: update of an ongoing multicenter study. Presented at the $5^{\text {th }}$ International Conference of Intraoperative Radiation Therapy; June 10-13, 2008; Madrid, Spain.

48. Sacchini V, Beal K, Goldberg J, et al. Study of quadrant high-dose intraoperative radiation therapy for early-stage breast cancer. Br J Surg 2008;95:1105-1110.

49. Dirbas F, Horst K. Intraoperative radiotherapy following lumpectomy for breast cancer. Semin Breast Dis 2007;10:26-33.

50. Ollila DW, Klauber-DeMore N, Tesche LJ, et al. Feasibility of breast preserving therapy with single fraction in situ radiotherapy delivered intraoperatively. Ann Surg Oncol 2007;14:660-669.

51. Baglan KL, Sharpe MB, Jaffray D, et al. Accelerated partial breast irradiation using 3D conformal radiation therapy (3D-CRT). Int J Radiat Oncol Biol Phys 2003;55:302-311.

52. Vicini FA, Chen $\mathrm{P}$, Wallace $\mathrm{M}$, et al. Interim cosmetic results and toxicity using $3 \mathrm{D}$ conformal external beam radiotherapy to deliver accelerated partial breast irradiation in patients with early-stage breast cancer treated with breast-conserving therapy. Int J Radiat Oncol Biol Phys 2007;69:1124-1130.

53. Vicini FA, Winter K, Straube W, et al. Initial efficacy results of RTOG 0319: three dimensional conformal radiation therapy (3D-CRT) confined to the region of the lumpectomy cavity for stage I/II breast carcinoma. Proceedings of the American Society for Therapeutic Radiology and Oncology 47th Annual Meeting 2008;72(1 Suppl 1):S3

54. Formenti SC, Truong MT, Goldberg JD, et al. Prone accelerated partial breast irradiation after breast-conserving surgery: preliminary clinical results and dose-volume histogram analysis. Int J Radiat Oncol Biol Phys 2004;60:493-504.

55. Polgar C, Fodor J, Major T, et al. Breast-conserving treatment with partial or whole breast irradiation for low-risk invasive breast carcinoma-5-year results of a randomized trial. Int J Radiat Oncol Biol Phys 2007;69:694-702.

56. Polgar C, Strnad V, Major T. Brachytherapy for partial breast irradiation: the European experience. Semin Radiat Oncol 2005; 15:116-122.

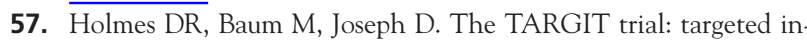
traoperative radiation therapy versus conventional postoperative whole-breast radiotherapy after breast-conserving surgery for the management of early-stage invasive breast cancer (a trial update). Am J Surg 2007;194:507-510.

58. Orecchia R. Milan-ELIOT randomized trial. in ISIORT 2008. Presented at the $5^{\text {th }}$ International Conference of Intraoperative Radiation Therapy; June 10-13, 2008; Madrid, Spain.

59. Clinicaltrials.gov. RAPID: Randomized Trial of Accelerated Partial Breast Irradiation. Available at: http://clinicaltrials.gov/ct2/show/ NCT00282035? recr $=$ open\& cond $=\% 22$ Cosmetics $\% 22 \&$ rank $=9$. Accessed December 16, 2008.

60. Current Controlled Trials. Randomised trial testing Intensity Modulated radiotherapy and Partial Organ RadioTherapy following breast conservation surgery for early breast cancer. Available at: http://www.controlled-trials.com/ISRCTN12852634/. Accessed December 15, 2008. 